\title{
Investigating the Impact of English for Specific Purposes (ESP) Curriculum on Moroccan Graduates' Career
}

\author{
Riham Belkbir \\ Faculty of Arts and Humanities, Sidi Mohammed Ben Abdullah University, Morocco \\ Riham.belkbir.chaoui@gmail.com
}

Received:
Kn/06/2019
Knowledge of a foreign language opens new possibilities of mobility and
cooperation for professionals in the contemporary world. Policy makers
acknowledge the important role that foreign languages, especially English,
play in the professional development of experts and try to present this
language at tertiary level. Generally, an ESP course is designed to improve
students' communication skills not merely for the exam, but also for situations
in a specific workplace. This paper investigates the impact that English for
Specific Purposes (ESP) curriculum has on Moroccan graduates in the career
experience. It also explores whether the ESP courses are more expedient in
the workplace than traditional English courses, and how ESP curriculum
Impact,
shallenges,
collected through online interviews from 6 participants whose majors were
Job Market
English and who graduated from Moroccan universities and all the participants
have at least one year of work experience in English-speaking countries. The
results of this research indicate that universities ESP curriculum design, work
place, and teachers' specific field knowledge do have notable influence on
participants in the work environment. They show that the current ESP in use
fails to capture the learners' needs and skills in the workplace communication.
The study divulges that there is a huge discrepancy of the perceptions of the
students' needs between the ESP teachers and employers in both academic
and occupational situations. Furthermore, the study's findings recommended
that Moroccan universities should re-design or develop their ESP curriculum
to allow their students meet the future job requirements as well as
supplementing extra materials through teachers'continual needs analysis.

\section{INTRODUCTION}

Nowadays, teaching English is spread in almost all those areas where its need for all jobs is felt. This increasing significance of the English language in the world engendered the accretion of one particular aspect of ELT namely English for Specific Purposes, henceforth ESP. It has grown to become one of the most conspicuous fields of EFL teaching today, and it becomes more effectual than other varieties of English language teaching. Its evolution is mirrored in the increasing numbers of universities propounding ESP courses. Particularly for Moroccan university students, ESP courses can help boost their occupational English skills, which can have a considerable impact on their profession. According to Caciora, Veronica and Amalia (2014):

ESP is a very broad domain, referring mainly to teaching English to students or people who need it for specific purposes such as work, or in their future occupational development. In these faculties, ESP is the main instrument for teaching a foreign language. In contrast to general English, ESP starts from the assessment of those functions and purposes for which 
English is required, as well as of the skills the learner might need most. (p.

59)

Although the majority of college or university students begin to study English when they are at middle school, they are still deficient in English language skills, which makes it difficult for them to habituate ESP courses at the start. Wu et al. (2014) found that most of students are not good at English, especially at speaking and listening. Hence, more investigation should focus on the language difficulties that Moroccan graduates encounter, or if there is any ESP syllabus that Moroccan universities should refine to meet the students' demands in their future working world with respect to English.

Previous studies of ESP teaching are principally qualitative with a concentration on the results of ESP. Yet, the qualitative approach gives the chance to include participants and the obtained data can improve teachers' comprehension of ESP curriculum and the actual working situation. By examining these diverse experiences, opting for qualitative methods and including participants, we can get a general idea about the benefits and drawbacks relating to ESP curriculum in Moroccan universities. On the report of this general understanding, we can come up with some recommendations on current ESP curriculum and teachers can change their teaching practices and objectives to serve the needs of students' professional development. The objectives of the investigation can be expressed in the following research questions:

1- What is the correlation between English for Specific Purposes and Moroccan Graduates' work environment?

2- What English language skills do employers require in the occupational context?

3- What language difficulties do Moroccan university graduates confront when working in foreign countries?

4- What suggestions do participants provide for the enhancement of the existing ESP syllabus in Moroccan universities?

\section{DEFINITION OF ESP}

Long ago, people started to feel the need to learn the English language for various reasons either to ensure better communication with others, to have access to resources of new information for students, researchers and workers, or to increase the chances of getting a good job in multilingual companies. Hence, the concern to make language courses more responsive to learners' needs has led to the emergence of a sub-field of English Language Teaching (ELT) under the denomination of "English for Specific Purposes" or "ESP" for short. While exploring the predominant rationale behind the growth of interests and attentiveness into learning English, one may discover different responses, as well as different motives. In this regard, Kennedy \& Bolitho (1984) state that "The growth of business and increased occupational mobility is resulting in a need for English as a common medium of communication, and access to much scientific and technical literature is difficult for those with no knowledge of English" (p. 1). Consequently, the internalization of education, business and industry have engendered the development of ESP. English language knowledge is not seen only as a starting point for effective communication, but also a crucial source of the technological development as it permits fast exchange of both knowledge and research in different domains.

It is still ambiguous to determine what is meant by ESP. Defining ESP has demonstrated to be so complex to scholars. Strevens (1977) emphasize that "producing a simple and straightforward definition of ESP is not an easy task" (p. 109). There are almost as many definitions of ESP as the number of researchers who tried to define it. Some scholars in 
the field of English for specific purposes describe it as the teaching of English for any reason that could be stated. Others, on the other hand, were more accurate, depicting it as the teaching of English for professional or occupational purposes. Exceptional reference should be made of the speedy growth of English for Academic Purposes (EAP) in the last few years by dint of the revolutionary research of scholars such as John Swales (e.g., 1985, 1990, 2004), Ken Hyland (e.g., 2006, 2009) and Ann Johns (2013). English for Occupational Purposes (EOP) is conventionally seen as the duplicate of English for Academic Purposes (EAP). According to Hutchinson and Walters' categorization (1987), EOP and EAP originate from three supreme ESP areas: English for Science and Technology (EST), English for Business and Economics (EBE), and English for Social Sciences (ESS). An additional terminology situates EOP and EAP as an uninterrupted branches extracted from ESP: (1) English for Occupational Purposes with educational activities for professional and vocational purposes and (2) English for Academic Purposes with courses mainly in medicine, science Business and Law (Dudley-Evans \& St John, 1998). Since ESP is considered to be a diverse field of ELT, it is pivotal to know what it really means. In this sense, a number of famous definitions related to the ESP context are presented to be discussed.

Mackay and Mountford (1978) write to this effect that ESP is the teaching of English for a "clearly utilitarian purpose" (p. 2). This implies that the goal depends on the needs of the learner which can be academic, scientific or occupational. The point is that learners should be taught in English in a way that enables them to use it in their future careers. These needs in turn shape the content of the ESP course to be taught and learned. The researchers also describe ESP as the 'special language' that occurs in specific contexts by some participants. They clarify that those participants are usually adults because they know particularly why they are learning the English language, and because they make real use of it in the special setting they work in. Accordingly, one can see how English is not a purpose in the learning process, but a means to achieve another purpose. In this respect, Robinson and Coleman (1989) advocate that learners study ESP not because of their interest in the English language but because they are required to do or complete an activity in English.

\section{THE CURRENT ESP SITUATION IN MOROCCO}

English for specific purposes has become a preeminent sphere of teaching/learning in Morocco during the last few decades. ESP education has also begun to be a medial pedagogical and educational matter of interest. If we want to give a comprehensive picture of the situation of ESP in Morocco, it can be said that Moroccan ESP teachers maintain various beliefs with reference to the field of ESP both in terms of theory and practice. In reality, their beliefs and perspectives are evidently echoed in their teaching practices.

In line with what has been mentioned earlier, and as far as the English language is concerned, we can say that Moroccan students' performance in the English language does not really allow them to speak, listen, write and read using English in specific fields. When requested about the importance of learning English, the general proclivity of many students is aware of its significance. They convey their exigency and motivation to learn the language and to improve their communication skills in it. In most educational environments, ESP is often observed to be taught by general English teachers. Despite the growing demand for courses in language for specific purposes, decision makers and curriculum designers have not realized its importance in the field of teaching/learning.

Although the language of instruction in Morocco is either Arabic or French, the Moroccan government that is aware of the indispensable role held by the English language, endeavours to implement the use of English at all levels of education. Zughoul (2003) claims: 
In Arab North Africa, and despite the fact that French has had a strong foothold in Tunisia, Algeria and Morocco, it has been retreating and losing a lot of ground to English. In fact, the tendency of what can be termed a shift from French to English in these countries cannot be cancelled. (p. 19)

In higher education, English is present in different departments nationwide, either as a fundamental subject by which students are required to attend some modules like: Linguistics, Literature, communication, Grammar and so forth; or as an additional but 'compulsory' module. The English department in Morocco has obtained new features that differentiate it from other departments in terms of content, methodology and assessment. Concerning content, English language courses have shifted their focus from old literary texts to modern ones, such as replacing Shakespeare by Edward Said. In terms of methodology, Ouakrime (1986) mentioned that there was a shift from teacher-cantered approach to learner- cantered approach. With reference to assessment, the English department is distinguished basically by various forms of assessment such as presentations, seminars, portfolios etc. In sum, these characteristics make it occupy a special place in Moroccan higher education system.

\section{LANGUAGE COURSE DESIGN}

ESP is considered to be a learner-cantered approach to teaching English as a foreign language. It meets the requirements of learners who need to learn a foreign language in order to use it in their specific fields, such as technology, business, science, and professional learning in which teachers take part in designing ESP courses to meet learners' demands. Hutchinson and Waters (1987) describe a course as "an integrated series of teaching-learning experiences, whose ultimate aim is to lead the learners to a particular state of knowledge" ( $p$. 65). To a degree, it is a series of actions and steps that include planning courses for the goal of learning a language. Accordingly, language courses whether ESP (English for Specific Purposes) or GE (General English) courses are well set through several stages. Course design in ESP according to Hutchinson and Waters is:

The process by which the raw data about learning needs is interpreted to produce an integrated series of teaching learning experiences, whose ultimate aim is to lead the learners to a particular state of knowledge. This entails the use of the theoretical and empirical information available to produce a syllabus, to adapt or write materials in accordance with the syllabus, to develop a methodology for teaching those materials and to establish evaluation procedures by which progress towards the specific goals will be measured. (p. 65)

In the context of ESP, course design is a process of gathering information to develop tasks and to design the most suitable setting for learners to reach their purposes. The process of planning and designing a suitable course that satisfies the demands of ESP groups can be very arduous. ESP teachers of such groups are often faced with different complications and problems when they are not well aware of the know-how of designing effective courses that will meet the specific needs of their learners. The principal element in designing an ESP course is the recognition of students' needs which may establish a sense of motivation in the learners' since they can bring their own contribution to it.

\section{METHOD}

\subsection{Instrument}

In order to acquire a thorough and overall knowledge of the existing ESP curriculum in Moroccan universities, and to be able to detect the different elements affecting Moroccan graduates' career, the researcher had resorted to workers' interviews. Therefore, the present 
study opted for a qualitative method, particularly a case study. For Merriam (1980), case studies are used for investigating a single person, group, event or community. Data are collected through different methods like interviews. The data are collected through online interviews from 6 participants whose specialties were English and who graduated from Moroccan universities and all the participants have at least one year of work experience in English-speaking countries.

\subsection{Procedure}

The researcher opted for deliberate sampling to select her potential participants because it helped me deliberately choose individuals and constructed an understanding of the phenomenon (Creswell, 2015). Because my study investigates the impact of ESP curriculum on Moroccan universities and graduates' job market, I selected some friends as my participants since they graduated from Moroccan universities in 2015, and they have worked in English-speaking countries approximately for one year. Investigating the graduates' requirements, assessing the present ESP teaching in Moroccan universities and making suggestions to ameliorate the ESP curriculum were the main aims of the present study. These intended participants can help to enlarge a comprehensive understanding about this study and may bring forth utilitarian data, as well as allow people study a phenomenon. One of the sampling strategies used in this research is maximum heterogeneity sampling so as to get as much insight as possible into the phenomenon under examination. According to Creswell (2015), this kind of purposeful sampling is one of the most frequently used. It allows the researcher to focus on specific characteristics of participants that are of interest. Another sampling method that Creswell (2015) suggests is critical case sampling which helped me bring to the fore the phenomenon of interest to learn and explore more things. For this study, these two tactics can help me to crosscheck, analyse and crosscheck data based on various contexts.

Data coding was also a crucial item to this research process. As stated by Creswell (2014), "a methods discussion in a qualitative proposal needs also to specify the steps in analysing the various forms of qualitative data" (p. 194). I gathered data via online skype, then I interpreted it into a Microsoft file and classified all files into various sub-items, which I analysed easily. In addition, I selected all the identical responses together in order to establish a more extensive understanding of the research questions. All the data collection and analysing techniques would secure the identity and secretiveness of participants. The six participants will be referred to as P1, P2, P3, P4, P5 and P6 respectively.

\section{RESULTS AND DISCUSSION}

After interviewing six Moroccan graduates who worked abroad for more than one year, the researcher was able to gather enough data for this study. Before the interview, participants received a short questionnaire to get background information from them. They were inquired to specify their specialization, when and where they graduated, what English course they sat for, and how long they had been working abroad. The main aim of this study was to explore the influence of ESP curriculum on Moroccan graduates in the workforce, and to establish comparability between the impact of general English and ESP courses. Thus, data was gathered based on four attributes:

- English courses taken at the university.

- The most and least useful courses at the university.

- The biggest difficulties faced at work.

- Suggestions for ESP Curriculum in Moroccan universities. 


\subsection{English Courses Taken at the University}

Based on the short questionnaire, each participant enumerated the English courses he had taken at the university. P1 said that she took Extensive Reading, Introduction to Translation, Communication English, Phonetics and Phonology, British and American Culture. P2 stated that he had Grammar, Drama and Novels, Spoken English, Paragraph Writing, Literary and Cultural Theories, and Research Methodology. P3 took Oral English, Translation, Reading Comprehension and Précis, Grammar, and British/ American Culture. P4 emphasized that she had Composition, Public Speaking and Debating, Business English, Advanced Grammar, Drama and Poetry. P5 noted that he took Literary Movements, Novels/ Poetry, Media Studies, Grammar, and Guided Reading. P6 declared that he had British and American Culture and Society, General Linguistics, and Business Communication. Most participants had the same general English courses in common, such as Reading, Translation, and British/American Literature. On the other hand, they had ESP courses like Business English and Oral Communication.

\subsection{The Most and Least Useful Courses at the University}

All the participants have been working for more than one year, and they took at least thirty English courses at the university. Among these courses, they discovered some were effective in their professional jobs, particularly, Oral Communication, Translation, as well as Public Speaking and Debating. P1, P2 and P3 stated Communication English and Translation were the most useful because they enlarged their vocabulary and speaking skills. For instance, P1 explained that Advanced English provided her the necessary means to better grasp paragraphs, academic articles, and even stories. She noticed that such skills were censorious to comprehend the broad connotations and implications of the language. She also added that vocabulary was crucial for her, regardless of which grammar or jargon she was involved in. Nevertheless, it was of particular importance to her professionally because her lacking vocabulary knowledge intercepted her from understanding what co-workers discussed. P3 emphasised that translation was vital for his professional career. It allowed him to express himself by using English idioms. He insisted that speaking good English was a priority within work settings. After her graduation, most of P4's work was associated mainly to international trading, and Business English courses allowed her to have a general understanding of international transactions. Therefore, this course trained her for the in-depth differences of her professional career and proved more important to her than the other English courses.

The majority of participants stated that the class of British and American literature was the least useful one in their universities. P5 explained that in this class, students were only asked to read novels. He added that the assessment part required him to memorize facts just to pass the exam; he did not get a thorough comprehension of Western culture. The same idea is confirmed by P2. Though he confessed that having a significant cultural understanding plays an important role in work settings, the class did not cover enough information to make it valuable. When he decided to work in a foreign country, he did some online research about the specifics of culture, and these were more interesting than what he learned in class. Likewise, P6 shared the same idea. He declared that his colleagues were not interested in The Old Man and the Sea or King Lear, or any other old novels. Although each participant had a different view about the degree of importance in each course, they made it clear that the professors had a program with respect to designing courses. They did not care about students' needs. To put it in a nutshell, the findings of the study showed that listening and speaking were ranked as the most needed English language skills, followed by writing and reading 
respectively. With regard to the speaking and listening activities, the English language was needed most in making face to face conversations such as talking to customers and small talks. Similarly, the writing skill was used to write professional emails.

\subsection{The Biggest Difficulties Faced at work}

All participants faced some difficulties related to communicating in English, when they first worked abroad. Most of them mentioned that the American/British accents were the most essential problems at the beginning of their work. P2, P3 and P4 had identical experiences. They all confirmed that the accents were inevitably different from those they learned in class. As English was not their mother tongue, they often needed native speakers to repeat what they said several times to get the real meaning. P5 and P6 remembered that they could only grasp $65 \%$ of what native speakers were saying at the beginning of their arrival. They needed approximately 3 months to become familiar with the local accents of the places they worked in. The majority of respondents agreed on the fact that understanding fast speech was the main challenge for them. On the contrary, P1 revealed that cultural differences were the biggest challenges during their work abroad. This is principally because the logic and ratiocination in Morocco differs from many Western countries, which may be embedded in culture. She suggested that workers should spend some time researching the country and its restrictions before heading off.

\subsection{Suggestions for ESP Curriculum in Moroccan universities}

Each participant proposed suggestions on how to enhance the ESP curriculum. For instance, P1 suggested that it would be important for universities to collaborate with companies to provide students with apprenticeship to demonstrate how students' background can be applied in different fields. Student learning cannot rely only on in-class lessons and textbooks to acquire knowledge; they need to learn it and employ it to the real work. In the same vein, P2 and P3explained that universities should prepare students by sending them to authentic companies. For instance, students who are planning to work in tourism should go to travel agencies to get real work experience, which students cannot acquire from textbooks. P3 added that "life teaching" is imminent because students need to learn from life not only from teachers. The idea of content knowledge was also reiterated by $\mathrm{P} 4$, who proffered that teachers should have equilibrium between field knowledge and the English language. Furthermore, P5 and P6 asserted that the biggest problem they encountered was their lack of work experience. For them, what they learned in the classroom was not enough to cope with their professional responsibilities.

\section{LIMITATIONS OF THE RESEARCH}

The present study only included six participants, each of whom only encountered familiar work experience in Britain and the United States of America. This may have been the origin of the cultural and pronunciation problems that participants faced. Moreover, participants' personalities and way of thinking may also have an impact on their job choice, which may not be taken into consideration by the ESP curriculum. Furthermore, three participants (P2, P3, and P6) studied in the same university. As a consequence, there are restricted suggestions due to an absence of multiplicity among the universities they have studied in. Therefore, this research cannot be a model of all the Moroccan ESP curriculum.

\section{IMPLICATIONS FOR FUTURE RESEARCH}

The current research's results recognize issues related to Morocco's ESP curriculum and presents some realistic suggestions that educators and course designers might consider when reshaping the ESP course. This implies that educators are required to take into account 
the practicality of coursed with regard to professional settings, and the critical difficulties students will face at work, exceptionally, upon their landing abroad. For future research, it can emphasise the impact of the ESP courses on non-English major graduates' career because this research focused only on the role of ESP courses on English subjects.

\section{CONCLUSION}

This study investigated the challenges that some Moroccan graduates faced when working abroad. Major findings indicated that students consider ESP as important and compulsory for their academic advancement whether in their current studies or their future work. Also, the research stressed that university education did not train them for their future jobs. Most of their point of views can be utilized as the basis for implications concerning future ESP curriculum design. They believed that using the textbook as the only instructional guide without any practice, will not approach the realities of individual learning situations. By getting to know the difficulties and the real requirements of learners, teachers will be able to assess the distance between classroom material and the needs of the workplace.

\section{References}

Caciora, A., Veronica, S., \& Amalia, S. (2014). Methods of evaluating learners studying English for special purposes. Annals of the University of Oradea. Economic Science, 23(1), 61-69.

Creswell, J. W. (2014). Research design: Qualitative, quantitative, and mixed methods Approaches. Los Angeles, CA: Sage Publications, Inc.

Creswell, J. W. (2015). Educational research: Planning, conducting, and evaluating quantitative and qualitative research (5th ed.). Boston, MA: Pearson Education.

Dudley-Evans, T., \& St John, M. (1998). Developments in ESP: A Multi-Disciplinary Approach. Cambridge: Cambridge University Press.

Hutchinson and Waters (1987). English for Specific Purposes: a learning centred approach. Cambridge: Cambridge University Press.

Hyland, K. (2006). English for Academic Purposes: An Advanced Resource Book. London: Routledge.

Hyland, K. (2009). Academic Discourse. London: Continuum.

Johns, A. M. (2013). The history of English for specific purposes research. The handbook of English for specific purposes, 5,30 .

Kennedy, C., \& Bolitho, R. (1984). English for Specific Purposes. London: Macmillan.

Mackay, R., \& Mountford, A. (1978). English for Specific Purposes: A Case Study Approach. London: Longman.

Merriam, S. B. (1998). Qualitative research and case study applications in education. Revised and Expanded from Case study research in education. San Francisco, CA: Jossey-Bass Publishers.

Ouakrime, M. (1986). English Language Teaching in Higher Education in Morocco: An Evaluation of the Fez Experience. Unpublished Ph. D Dissertation. University of London.

Coleman, H. (Ed.). (2011). Working with language: A multidisciplinary consideration of language use in work contexts (Vol. 52). Walter de Gruyter.

Strevens, P. (1977). New Orientations in the Teaching of English. Oxford: Oxford University Press. 
Swales, J. (1985). Episodes in ESP: A Source and Reference Book on the Development of English for Science. Oxford: Pergamon Press Ltd.

Swales, J. (1990). Genre Analysis: English in Academic and Research Settings. Cambridge: Cambridge University Press.

Swales, J. (2004). Research Genres: Explorations and Applications. Cambridge: Cambridge University Press.

Wu, R., Wu, R., \& Le, V. T. (2014). Challenges of adults in learning English as a second language: Focus on adult education in China. Journal of Language Teaching and Research, 5(5), 11321138.

Zughoul, M. R. (2003). Globalization and EFL/ESL Pedagogy in the Arab World. 